\title{
Measuring Vocabulary Learning Strategy Use of Turkish EFL Learners in Relation to Academic Success and Vocabulary Size
}

\author{
Özkan Kırmız1, ${ }^{1, *}$ \\ ${ }^{1}$ Karabuk University, Department of English Language and Literature, Turkey \\ *Correspondence: Karabuk University, Department of English Language and Literature, Turkey. E-mail: \\ ozkankirmizi@karabuk.edu.tr
}

Received: October 14, 2014

Accepted: November 4, $2014 \quad$ Online Published: November 12, 2014

doi:10.5430/wje.v4n6p16

URL: http://dx.doi.org/10.5430/wje.v4n6p16

\begin{abstract}
The purpose of this study was to investigate Vocabulary Learning Strategy (VLS) use of English Language and Literature Department students in relation to academic success and vocabulary size. The participants of the study are 213 English Language and Literature students. Two data collection tools were used in the study. The first tool was theVocabulary Learning Strategy (VLS) questionnaire which was adapted from by Gu \& Johnson (1996), and the second data collection tool was a Vocabulary Level Test (VLT) developed by Nation (1983).Descriptive statistics were conducted in order to measure the level of vocabulary learning strategy (VLS) use and vocabulary size of the participants. In addition, correlation analysis was carried out in order to see which VLSs are more frequently used by low, middle and upper level vocabulary size students. The results indicated that the participants have a high level of vocabulary size for 2000 word level, 3000 word level, and academic word levels, a moderate level of vocabulary size for 5000 word level and a low level in 10000 word level. The participants were found to have a moderate level of vocabulary learning strategy use. The study also found that $3^{\text {rd }}$ grade students had larger vocabulary size in terms of 2000,3000 and academic vocabulary level. As for the vocabulary strategy use, $3^{\text {rd }}$ grade students were found to use bottom-up strategies and note-taking strategies more frequently than $2^{\text {nd }}$ grade students. Finally, correlation analysis revealed that bottom-up strategies, using linguistic clues, and top-down strategies significantly correlated with academic success.
\end{abstract}

Keywords: vocabulary learning strategy; vocabulary size; word level

\section{Introduction}

Vocabulary learning is one of the major and essential components of mastering a foreign language; nevertheless, it is often either neglected or eliminated in language related departments like English Language Teaching department or English Language and Literature departments in the Turkish context. Therefore, insufficient vocabulary instruction leads to inadequate vocabulary acquisition on the part of students. Students in these departments are expected to develop their own vocabulary size without instruction. Stæhr $(2008$, p. 1) states that "vocabulary knowledge is generally assumed to be a good predictor of language proficiency in a second or a foreign language."Alderson (2005) also found that vocabulary had a strong relationship with reading, listening, writing, speaking and grammar. Thus, it is possible to argue that language ability in general mainly boils down to sound vocabulary knowledge (Alderson, 2005).

In literature, there are a number of studies that point to the relation between vocabulary size and learners' strategy use (Lawson and Hogben, 1996; Schmitt, 1997; and Fan, 2003). A number of recent studies focused on the relationship between vocabulary learning strategy use and vocabulary size(Hamzah, et all, 2009; Kafipour, et al, 2011; Komol\&Sripetpun, 2011; Kalajahi\&Pourshahian, 2012). Most of these studies found that vocabulary learning strategies contributed to the overall vocabulary learning of the learners.

\subsection{Vocabulary Learning Strategies}

According to Nation (2001), vocabulary learning strategies are among language learning strategies. VLSs are defined as "the actions that learners take to help themselves understand and remember vocabulary items" (Cameron, 2001, p. 
92). VLSs are also defined as:

the mechanism used in order to learn vocabulary as well as steps or actions taken by students (a) to find out the meaning of unknown words, (b) to retain them in long-term memory, (c) to recall them at will, and (d) to use them in oral or written mode" (Catalan, 2003, p. 56).

There are a number of different classification patterns for VLSs. An earlier version proposed by O'Malley et al. (1985) claimed the use of 24 strategies employed by learners of English. These strategies were "Metacognitive", "Cognitive", and "Socio-affective" strategies. Oxford (1990) proposed a classification in which there were direct and indirect strategies. According to her, direct strategies contain "Memory", "Cognitive",and "Compensation" strategies while indirect strategies include "Metacognitive", "Affective", and "Social" strategies.Schmitt (1997) categorized vocabulary learning strategies into determination strategies, social strategies, memorization strategies, cognitive and metacognitive strategies. Gu (2003) classified second language (L2) vocabularylearning strategies as cognitive, metacognitive, memory and activationstrategies. The present study used the taxonomies of Gu.

\subsection{Research on Vocabulary Learning Strategies}

Vocabulary learning strategies have been studied since the last decade both in breath and in depth in experimental and descriptive studies. Zarafshan (2002) explored why Iranian EFL learners make little use of metacognitive strategies and found that curriculum design does not promote collaborative and social learning. The study found that adult learners used more sophisticated strategies including memory and cognitive strategies. This finding is in line with Oxford's (1990) belief that adult learners tend to use more sophisticated VLS. Zarafshan'sstudy (2002) indicatedthe importance of formal training on strategy development. To justify this in the Turkish context, Aktekin and Güven(2007) worked on raising learners' and teachers' awareness on vocabulary learningstrategy and their study discovered that providing vocabulary learning strategy instruction had a significant positive effecton the vocabulary learning of students. Quite recently, Boonkongsaen and Intaraprasert (2014) conducted a study on the effects of fields of study (arts, business and science-oriented, and language-learning experiences (whether limited or non-limited to formal classroom instructions) on the use of VLSs among Thai tertiary-level students. They found that field of study affected the students' overall VLS use.

There are a number of studies that focus on vocabulary learning strategies in relation to different variables. T1lfarlığlu and Bozgeyik (2012) studied L2 learners' VLS use habits and the relationship between VLS and their vocabulary proficiency levels. The study found that the participants used a wide range of VLS, and there was a significant correlation between their beliefs about VLS in terms of usefulness and how often they used them. In addition, they found that memory strategies correlated positively with the participants' academic and general vocabulary proficiency levels. In another study, Tüm (2012) worked on the effects of dictionary use on learning Turkish words and found that learning new Turkish words is complicated but it can be overcome by using appropriate dictionary strategies.

There are also a number of studies that specifically focus on vocabulary learning strategies and vocabulary size. Quite recently, Tanyer and Öztürk (2014) carried out a study that focused on pre-service teachers' vocabulary learning strategy use and vocabulary size. Their study found that the most frequently used strategies were determination strategies despite the fact that it was not influential on pre-service teachers' vocabulary stock. Further analysis revealed that the participants' vocabulary learning strategy use explained $17.8 \%$ of the variation in their vocabulary size. Alemdari's study (2010) found that the most preferred strategies by the students were cognitive, determination and social strategies and a relationship between successful vocabulary learning and use of cognitive and social strategies was found. Kalajahi and Pourshahian (2012) conducted a study on the relationship between VLS and vocabulary size. The results showed that there are no considerable correlations between VLS and vocabulary size of EFL learners in Cyprus.

\subsection{Vocabulary Size of Language Learners}

The number of words a learner has in mental lexicon is referred to as vocabulary size. Nation (1990) worked on this issue extensively and suggested that about $87 \%$ of the wordsin the textshe studied were the most frequent 2,000 headwords (base words) of English. The academic words which occurfrequently in most kinds of academic texts, technical words and low-frequency words account for the remaining $8 \%, 3 \%$ and $2 \%$ of the text, respectively.Thus, Nation (1990) concluded that all learners need to know about 2,000 to 3,000 wordlevel in order to function effectively in English.

In a similar vein, Laufer (1997) suggested that the threshold vocabulary size essential for reading comprehension was about 3,000 word level. Learners below the 3,000-word level performed poorly on the reading test regardless of how 
high their academic ability was. In terms of text coverage, the 3,000 word families were reported to provide coverage of between $90 \%$ and $95 \%$ of any text. Furthermore, Hirsh and Nation (1992) believe that it is necessary to have good knowledge of at least 5,000 words if someone aims to read advanced, authentic, academic texts. To conclude, 2,000 high-frequency words level is suggested for effective basic language use and successful text comprehension requires a vocabulary size of 3,000 to 5,000. Therefore, the lowest level for vocabulary size is 2000 words level (Nation, 2005 ) and the average level for effective language learning and comprehension is 5,000 word level (Schmitt, 2000).

\subsection{Research Questions}

1. Which vocabulary learning strategies are common among English Language and Literature department students?

2. What is the vocabulary size of English Language and Literature department students?

3. Are there any differences between second grade and third grade students in terms of vocabulary size and vocabulary learning strategies?

4. Do vocabulary strategy use and vocabulary size change based on academic success?

5. Which vocabulary learning strategies are associated with each vocabulary size level?

\section{Methodology}

\subsection{Participants}

The study was carried out with 130 English Language and Literature department students. The number of female students is $96(67.1 \%)$, and the number of male students is $34(23.8 \%)$. In terms of status, the number of regular students is $66(46.2 \%)$, evening students $56(39.2 \%)$, and distance education students $3(2.1 \%)$. When it comes to grade level, $60(42.0 \%)$ of the participants are second grade students, $64(44.8 \%)$ of the students are third grade students, and $4(2.1 \%)$ of them are fourth grade students. All groups of students, regular, evening, and distance education students, are exposed to the same teaching program.

\subsection{Data Collection Tools}

Vocabulary learning questionnaire: The research instrument was a Vocabulary Learning Strategy questionnaire which is an adapted version proposed by Gu \& Johnson (1996). The questionnaire consists of forty-six vocabulary learning strategies statements in addition to demographic information like department, gender, status and English grade of the students. The data consists of three parts and were analyzed through SPSS (Statistical Package for the Social Sciences). The first part included four questions asking the learners' department, gender, status and English grade. The second part contained forty-six items which were divided into eight categories including "beliefs about vocabulary learning (items 1-11), metacognition regulation (items 12-18), guessing strategies (items 19-25), dictionary strategies (items 26-32), note-taking strategies (items 33-37), memory/ repetition strategies (items 38-41), activation strategies (items 42-43), and anxiety (items 44-46). All these items were evaluated in terms of 5 points rating scale such as 1 point for "never" and 5 point for "always".

The Vocabulary Levels Test: The Vocabulary Levels Test (VLT) was originally devised by Nation (1983). The present study used Version 1, which consists of five parts, representing the following five levels of word frequency in English: the levels of 2000, 3000, 5000 and 10000 words and academic words. The 2000 and 3000 word levels contain high-frequency words. The 5000 word level represents the ultimate boundary of high and low-frequency items. The words below this threshold are central if one wishes to read authentic texts fairly fluently. The 10000 word level contains low-frequency items. L2 learners within 10000 word level can be considered proficient as he can read practically any texts, apart fromspecialized materials, without major difficulty (Merikivi and Pietilä, 2014). Finally, the academic word level is based on Coxhead's (2000) Academic Word List. This level of formal words contains specialized vocabulary important for learners.

\subsection{Data Analysis}

The study initially employs descriptive statistics in order to measure the frequency of vocabulary strategy use of the students and their vocabulary size. Then, in order to investigate whether vocabulary learning strategies and vocabulary size differ in terms of gender or grade level, two t-tests were run. Finally, in order to find out the influence of vocabulary learning strategies on vocabulary size and which vocabulary learning strategies match with which vocabulary size, correlation analyses were carried out. 


\section{Results}

Research question 1: Which vocabulary learning strategies are common among English Language and Literature department students?

The first aim of the study was to measure the use of vocabulary learning strategies on the part of the participants. Table 1 presents descriptive statistics about general vocabulary learning strategies employed by English Language and Literature department students. Table 1 shows that the participants have a moderate level of beliefs about vocabulary learning $(M=13.97 ; S D=2.89)$, bottom-up strategies $(M=11.31 ; S D=2,20)$, top-down strategies $(M=11,17$; $\mathrm{SD}=2,46)$, selective attentionstrategies $(\mathrm{M}=12.46 ; \mathrm{SD}=18)$, using background knowledge $(\mathrm{M}=14.30 ; \mathrm{SD}=2.54)$, using linguistic clues $(\mathrm{M}=10.42 ; \mathrm{SD}=2.43)$, dictionary strategies $(\mathrm{M}=21.03 ; \mathrm{SD}=4.01)$, note-taking strategies $(\mathrm{M}=15.83$; $\mathrm{SD}=3.71)$, memory strategies $(\mathrm{M}=14.29 ; \mathrm{SD}=2.89)$, and evaluation strategies $(\mathrm{M}=16.26 ; \mathrm{SD}=3.56)$. Interestingly, the participants have considerably low level of self-initiation strategies $(\mathrm{M}=10.84 ; \mathrm{SD}=4.92)$. The results indicate that the participants have a moderate level of vocabulary learning strategy use.

Table 1. Descriptive Statistics about Vocabulary Learning Strategies

\begin{tabular}{llrrrr}
\hline VLS & & & & & Std. \\
& N & Minimum & Maximum & Mean & Deviation \\
\hline beliefs & 130 & 7,00 & 22,00 & 13,9769 & 2,89202 \\
bottom-up strategies & 130 & 5,00 & 18,00 & 11,3154 & 2,20653 \\
top-down strategies & 130 & 5,00 & 18,00 & 11,1769 & 2,46358 \\
self-initiation strategies & 130 & 4,00 & 53,00 & 10,8462 & 4,92338 \\
selective attention & 130 & 8,00 & 16,00 & 12,4692 & 1,86435 \\
using background knowledge & 130 & 7,00 & 20,00 & 14,3000 & 2,54464 \\
using linguistic clues & 130 & 3,00 & 15,00 & 10,4231 & 2,43955 \\
dictionary strategies & 130 & 1,00 & 31,00 & 21,0385 & 4,01046 \\
note-taking strategies & 130 & 5,00 & 25,00 & 15,8385 & 3,71630 \\
memory strategies & 128 & 4,00 & 20,00 & 14,2969 & 2,89816 \\
evaluation strategies & 130 & 8,00 & 25,00 & 16,2692 & 3,56292 \\
\hline
\end{tabular}

\section{Research question 2: What is the vocabulary size of English Language and Literature department students?}

The second research question addresses the vocabulary size of English Language and Literature department students. The results are presented in Table 2. As we can understand from the table, the participants have relatively high level in 2000 word level $(\mathrm{M}=9.10 ; \mathrm{SD}=1.88)$, a moderate level in 3000 word level $(\mathrm{M}=7.83 ; \mathrm{SD}=2.56)$, a relatively low level in 5000 word level $(\mathrm{M}=6.0 ; \mathrm{SD}=2.56)$, and a seriously low level in 10000 word level $(\mathrm{M}=2.93 ; \mathrm{SD}=2.26)$. In terms of academic vocabulary, we can see that the participants have a moderate level of proficiency $(\mathrm{M}=19.72$; $\mathrm{SD}=5.42$ ).

Table 2. Descriptive Statistics about Vocabulary Size of the Participants

\begin{tabular}{llcccc}
\hline Vocabulary size & $\mathrm{N}$ & minimum & maximum & Mean & Std. deviation \\
\hline 2000 word level & 130 & 2,00 & 12,00 & 9,1077 & 1,88526 \\
3000 word level & 130 & 1,00 & 12,00 & 7,8385 & 2,56634 \\
5000 word level & 130 & 1,00 & 12,00 & 6,008 & 2,5684 \\
10000 word level & 130 & 0,00 & 12,00 & 2,9385 & 2,26792 \\
Academic vocabulary & 130 & 1,00 & 29,00 & 19,7231 & 5,42177 \\
\hline
\end{tabular}

In order to understand the vocabulary level of the participants better, the data have been further tabulated based on low, moderate and high levels. The results are presented in Table 3. As we can understand from Table 3, in 2000 word level most of the participants have a high level of proficiency and a relatively lower level of proficiency for 3000 word level. When it comes to 5000 word level, we can see that most of the participants have a moderate level of proficiency. For 10000 word level, a seriously large number of the students have a low level of proficiency. Finally, as for academic vocabulary most of the students have a high level of proficiency. 
Table 3. Descriptive Statistics about Vocabulary Size of the Participants Based on Low, Moderate, and High Levels

\begin{tabular}{lllllll}
\hline Vocabulary size & \multicolumn{3}{c}{ Low } & \multicolumn{2}{c}{ Moderate } & \multicolumn{2}{c}{ high } \\
\hline & $f$ & $\%$ & $f$ & $\%$ & $f$ & $\%$ \\
2000 word level & 2 & 0.15 & 36 & 27 & 92 & 70 \\
3000 word level & 15 & 11 & 57 & 43 & 58 & 44 \\
5000 word level & 35 & 26 & 73 & 56 & 22 & 16 \\
10000 word level & 115 & 88 & 11 & .08 & 3 & .02 \\
Academic vocabulary & 4 & .03 & 62 & 47 & 64 & 49 \\
\hline
\end{tabular}

Research question 3: Are there differences between second grade and third grade students in terms of vocabulary size and vocabulary learning strategies?

The next research questions deals with the differences between second and third level students in terms of vocabulary learning strategy use and vocabulary size. The results are presented in Table 4 . as we can understand form the table, there are statistically significant differences between second and third grade students in terms of 2000 word level $(\mathrm{p}<.05), 3000$ word level $(\mathrm{p}<.05)$, and academic vocabulary $(\mathrm{p}<.05)$. We can understand form Table 4 that the mean scores of third grade students are higher than second grade students. The mean score for second grade students for 2000 word level is 8.4667 , while the mean score for the third grade students is 9.6875 . The mean score for second grade students for 3000 word level is 7.2500 , while the mean score for the third grade students is 8.3594 . Finally, the mean score for second grade students for academic vocabulary is 18.7667 , while the mean score for the third grade students is 20.7656 . We can understand that the mean scores for the third grade students are higher than the second grade students. This suggests that vocabulary size of the students increases as they continue their education. It can also be speculated that peripheral vocabulary learning plays a role in the increase of the vocabulary size.

Table 4. T-test Results for Grade Levels and Vocabulary Size

\begin{tabular}{llllll}
\hline & grade & $\mathrm{N}$ & $\mathrm{M}$ & $\mathrm{F}$ & Sig. \\
\hline \multirow{2}{*}{2000 word level } & 2. grade & 60 & 8,4667 & .250 & .000 \\
& 3. grade & 64 & 9,6875 & & \\
\multirow{2}{*}{5000 word level word level } & 2. grade & 60 & 7,2500 & .370 & .016 \\
& 3. grade & 64 & 8,3594 & & \\
\multirow{2}{*}{10000 word level } & 2. grade & 60 & 5,833 & 2.505 & .412 \\
\multirow{2}{*}{ Academic vocabulary } & 3. grade & 64 & 6,219 & & \\
& 2. grade & 60 & 2,6333 & 2.08 & .158 \\
& 3. grade & 64 & 3,2188 & & \\
& 2. grade & 60 & 18,7667 & .120 & .040 \\
\hline
\end{tabular}

The next point addressed by research questions 3 is whether there are statistically significant differences between second grade and third grade students in terms of vocabulary strategy use. The results are presented in Table 5. As we can understand form Table 6 , there are no statistically significant differences between $2^{\text {nd }}$ and $3^{\text {rd }}$ grade students in terms of beliefs about vocabulary learning ( $>.05)$, top-down strategies $(p>.05)$, self-initiation strategies $(p>.05)$, selective attention ( $>>05)$, using background knowledge ( $>>05)$, dictionary strategies $(p>.05)$, memory strategies $(p>.05)$, and evaluation strategies $(p>.05)$. However, statistically significant differences were observed between $2^{\text {nd }}$ grade and $3^{\text {rd }}$ grade students in terms of bottom-up strategies $(\mathrm{p}<.05)$, note-taking strategies $(\mathrm{p}<.05)$, and using linguistic clues $(\mathrm{p}<.05)$. This means that as learners move up to the $3^{\text {rd }}$ year they become more proficient in identifying the meanings of most words through reading, expanding their vocabulary through reading a lot. This can be explained by the fact that as learners move to $3^{\text {rd }}$ year, they have to read more academic texts on literature, language teaching, and linguistics. As a result, they develop themselves in the stated strategies. As for note-taking strategies, there are no statistically significant differences in terms of "I have a vocabulary note book to list down new word", "I only take note the meaning of the word", "I take note of the usages of the word" and "I take note of the synonym or antonym of the word". The only item that $2^{\text {nd }}$ grade and $3^{\text {rd }}$ grade students differed in the second items in the questionnaire: "I write down the English word and Arabic/Malay translation of the word". This shows that 3rd grade students rely more on writing down Turkish translations of the words they learn. Finally, in relation to using linguistic clues, the only point where 2 nd and 3rd grade students differed was the item "I make use of my knowledge of the topic to guess the meaning of word". This finding strengthens the view that as learners need to read 
more academic texts as they continue their education, they develop their skills in guessing vocabulary from context.

Table 5. T-test Results for Grade Levels andVocabulary Learning Strategies

\begin{tabular}{|c|c|c|c|c|c|}
\hline Variables & status & $\mathrm{N}$ & $\mathrm{M}$ & $\mathrm{F}$ & Sig. \\
\hline \multirow[t]{2}{*}{ beliefs about vocabulary learning } & 2. grade & 60 & 13,7833 & ,017 & ,593 \\
\hline & 3. grade & 64 & 14,0625 & & \\
\hline \multirow[t]{2}{*}{ bottom-up strategies } & 2. grade & 60 & 10,8333 & ,026 & ,023 \\
\hline & 3. grade & 64 & 11,7500 & & \\
\hline \multirow[t]{2}{*}{ top-down strategies } & 2. grade & 60 & 11,0500 & 2,138 & ,786 \\
\hline & 3. grade & 64 & 11,1719 & & \\
\hline \multirow[t]{2}{*}{ self-initiation strategies } & 2. grade & 60 & 10,1500 & 1,866 & ,155 \\
\hline & 3. grade & 64 & 11,4375 & & \\
\hline \multirow[t]{2}{*}{ selective attention } & 2. grade & 60 & 12,1333 & ,010 & ,068 \\
\hline & 3. grade & 64 & 12,7500 & & \\
\hline \multirow[t]{2}{*}{ using background knowledge } & 2. grade & 60 & 14,2833 & 463 & 842 \\
\hline & 3. grade & 64 & 14,3750 & & \\
\hline \multirow[t]{2}{*}{ using linguistic clues } & 2. grade & 60 & 9,9500 & 1,234 & 041 \\
\hline & 3. grade & 64 & 10,8594 & & \\
\hline \multirow[t]{2}{*}{ dictionary strategies } & 2. grade & 60 & 20,6333 & 2,355 & 377 \\
\hline & 3. grade & 64 & 21,2656 & & \\
\hline \multirow[t]{2}{*}{ note-taking strategies } & 2. grade & 60 & 15,0000 & 3,602 & ,033 \\
\hline & 3. grade & 64 & 16,4375 & & \\
\hline \multirow[t]{2}{*}{ memory strategies } & 2. grade & 60 & 14,1356 & 234 & ,717 \\
\hline & 3. grade & 64 & 14,3281 & & \\
\hline \multirow[t]{2}{*}{ evaluation strategies } & 2. grade & 60 & 15,7000 & ,466 & , 146 \\
\hline & 3. grade & 64 & 16,6406 & & \\
\hline
\end{tabular}

Research question 4: Do vocabulary strategy use and vocabulary size change based on the grade average of the students?

The relation between frequency of vocabulary strategy use and vocabulary size has been investigated within the scope of the study. The results are presented in Table 6.

Table 6. Correlation between Vocabulary Strategy Use and Vocabulary Size

\begin{tabular}{|c|c|c|c|c|c|c|c|c|c|c|c|c|}
\hline Strategies & Average & $\begin{array}{l}\text { Voc. } \\
\text { Size }\end{array}$ & Beliefs & Bottomup & $\begin{array}{c}\mathrm{T} . \\
\text { Down }\end{array}$ & Selfini & Selective & Background & Lingclues & Dictionary & Notetaking & Memory \\
\hline Beliefs & .060 & $.197^{*}$ & & & & & & & & & & \\
\hline Bottomup & $.312^{*}$ & $.219^{*}$ & $.274^{*}$ & & & & & & & & & \\
\hline Topdown & $.196^{*}$ & $.189^{*}$ & $.305^{*}$ & $.405^{*}$ & & & & & & & & \\
\hline Selfini & -.022 & .059 & $.208^{*}$ & .164 & $.246^{*}$ & & & & & & & \\
\hline Selective & .115 & .043 & $.333^{*}$ & $.305^{*}$ & $.341^{*}$ & .118 & & & & & & \\
\hline Background & .144 & .130 & $.248^{*}$ & $.451^{*}$ & $.432^{*}$ & .111 & $.222^{*}$ & & & & & \\
\hline Lingclues & $.237^{*}$ & $.207^{*}$ & $.248^{*}$ & $.401^{*}$ & $.563^{*}$ & $.258^{*}$ & $.348^{*}$ & $.424^{*}$ & & & & \\
\hline Dictionary & .075 & .068 & $.238^{*}$ & $.284^{*}$ & $.409^{*}$ & $.201^{*}$ & .164 & $.394^{*}$ & $.387^{*}$ & & & \\
\hline Notetaking & .098 & .097 & $.379^{*}$ & .143 & $.250^{*}$ & .073 & $.341^{*}$ & $.204^{*}$ & $.367^{*}$ & $.364^{*}$ & & \\
\hline Memory & .075 & .026 & $.315^{*}$ & $.192^{*}$ & $.441^{*}$ & $.231^{*}$ & $.380^{*}$ & $.278^{*}$ & $.452^{*}$ & $.254^{*}$ & $.415^{*}$ & \\
\hline Average & & $.546^{*}$ & .060 & $.312^{*}$ & $.196^{*}$ & -.022 & .115 & .144 & $.237^{*}$ & .075 & .098 & .075 \\
\hline
\end{tabular}

Notes: ${ }^{*} p<.05 ; * * p>.01$

Average: grade average, Voc. Size: vocabulary size, Beliefs: beliefs about vocabulary learning, Bottomup: bottom-up strategies, T.Down: top-down strategies, Selfini: self-initiation strategies, Selective: selective attention strategies,Background: using background knowledge, Lingclues: using linguistic clues, Dictionary: dictionary strategies, Notetaking: note-taking strategies, Memory: memory strategies

As we can understand from Table 6, there are three vocabulary learning strategies that are closely related to academic success. These strategies are bottom-up strategies $(r=.312, p<.05)$, using linguistic clues $(r=.237, p<.05)$, and top-down strategies $(r=.196, p<.05)$. Therefore, it can be said that the frequency of these three vocabulary 
learning strategy use increases as academic success increases. In addition, a positive and moderate level of correlation was observed between vocabulary strategy use and vocabulary size $(r=.546, p<.05)$. Depending on this finding, we can say that vocabulary strategy use increases as vocabulary size increases.

Research question 5: Which vocabulary learning strategies are associated with each vocabulary size level?

Within the scope of the study, in order to investigate the vocabulary strategy use frequency of the participants, the vocabulary levels of the participants in terms of 2000 word level, 3000 word level, 5000 word level, 10000 word level, and academic vocabulary were determined by calculating the correct answers. The results indicated that $33 \%$ of the participants were between $0-41$, the ones from $33 \%$ to $67 \%$ ranged from 42 to 51 , and the rest ranged from52 to 70 out of 78 possible correct answers. These numbers were used to categorize the participants in terms of their vocabulary size as low level, middle level, and upper level. The results are presented in Table 7.

Table 7. Descriptive Statistics Regarding Vocabulary Size and Vocabulary Strategy Use

\begin{tabular}{|c|c|c|c|c|}
\hline Vocabulary size & Strategy & $\mathrm{n}$ & $\bar{X}$ & $S S$ \\
\hline \multirow{10}{*}{$\begin{array}{c}\text { Low level } \\
(0-41 \text { correct } \\
\text { answers out of } 78)\end{array}$} & Beliefs & 40 & 3,42 & 0,73 \\
\hline & Bottomup & 40 & 3,61 & 0,82 \\
\hline & Topdown & 40 & 3,59 & 0,88 \\
\hline & Selfini & 40 & 3,58 & 1,72 \\
\hline & Selective & 40 & 4,13 & 0,61 \\
\hline & Background & 40 & 3,47 & 0,71 \\
\hline & Lingclues & 40 & 3,34 & 0,81 \\
\hline & Dictionary & 40 & 3,43 & 0,65 \\
\hline & Notetaking & 40 & 3,06 & 0,69 \\
\hline & Memory & 40 & 3,59 & 0,69 \\
\hline \multirow{10}{*}{$\begin{array}{c}\text { Middle level } \\
\text { (42-51 correct } \\
\text { answers out of } 78)\end{array}$} & Beliefs & 45 & 3,55 & 0,58 \\
\hline & Bottomup & 45 & 3,90 & 0,70 \\
\hline & Topdown & 45 & 3,70 & 0,82 \\
\hline & Selfini & 45 & 3,79 & 2,21 \\
\hline & Selective & 45 & 4,22 & 0,71 \\
\hline & Background & 45 & 3,62 & 0,65 \\
\hline & Lingclues & 45 & 3,46 & 0,85 \\
\hline & Dictionary & 45 & 3,57 & 0,70 \\
\hline & Notetaking & 45 & 3,31 & 0,75 \\
\hline & Memory & 45 & 3,60 & 0,86 \\
\hline \multirow{10}{*}{$\begin{array}{c}\text { Upper level } \\
(52-70 \text { correct } \\
\text { answers out of } 78)\end{array}$} & Beliefs & 45 & 3,52 & 0,85 \\
\hline & Bottomup & 45 & 3,79 & 0,68 \\
\hline & Topdown & 45 & 3,87 & 0,76 \\
\hline & Selfini & 45 & 3,47 & 0,59 \\
\hline & Selective & 45 & 4,12 & 0,54 \\
\hline & Background & 45 & 3,63 & 0,55 \\
\hline & Lingclues & 45 & 3,61 & 0,77 \\
\hline & Dictionary & 45 & 3,51 & 0,66 \\
\hline & Notetaking & 45 & 3,12 & 0,78 \\
\hline & Memory & 45 & 3,56 & 0,64 \\
\hline
\end{tabular}

Average: grade average, Voc. Size: vocabulary size, Beliefs: beliefs about vocabulary learning, Bottomup: bottom-up strategies, T.Down: top-down strategies, Selfini: self-initiation strategies, Selective: selective attention strategies,Background: using background knowledge, Lingclues: using linguistic clues, Dictionary: dictionary strategies, Notetaking: note-taking strategies, Memory: memory strategies

As we can understand from Table 7, the vocabulary learning strategies that are frequently used by the low level group are selective attention and bottom-up strategies, and the least used strategy is note taking strategies and using linguistic clues. The students in the middle level were also found to use selective attention and bottom-up strategies most frequently and note-taking and using linguistic clues the least frequently. As for the upper level group, the results indicate that these students use selective attention strategies and top-down strategies more frequently than the other strategies and the least used strategies by the upper level group are note-taking strategies and dictionary strategies. Based on these findings, it is possible to say that there are minor differences in vocabulary learning 
strategies in relation to their vocabulary size and although the same strategies seem to be used by students from all groups, their mean scores differ.

\section{Discussion}

The present study has been carried out in order to investigate vocabulary strategy use of Turkish EFL learners in relation to academic success and vocabulary size. To this end, the frequency of vocabulary strategy use of Turkish students was measured and the results indicated a high frequency of VLS use. For the same purpose, Turkish EFL students' vocabulary size was also measured and it was found that the participants had a high level of vocabulary in 2000,3000 , and academic vocabulary word level whereas the participants had a moderate level in 5000 word level and a low level in 10000 word levels. The study also found differences between $2^{\text {nd }}$ grade and $3^{\text {rd }}$ grade students in terms of vocabulary size. Third level students ranked higher in terms of 2000, 3000, and academic vocabulary sizes. This shows that vocabulary stock of students increase as they move up to upper grades, which justifies that peripheral vocabulary learning processes are at hand.

Another major finding of the study is that statistically significant differences were found between $2^{\text {nd }}$ grade and $3^{\text {rd }}$ grade students in terms of bottom-up strategies, note-taking strategies, and using linguistic clues. Third grade students relied more on writing down the Turkish equivalent of a new word, and they were found to be better at guessing vocabulary from context. It was hypothesized that as learners need to read more academic texts as they continue their education, they develop their skills in guessing vocabulary from context.

One of the major findings of the present study is that academic success highly correlated with bottom-up strategies, using linguistic clues, and top-down strategies. Bottom-up strategies are mostly related to reading and vocabulary development. Therefore, we can speculate that academic reading texts that students are supposed to read throughout their courses contribute to their vocabulary strategy development. Different studies produced different results in Turkish context. T1lfarlığlu and Bozgeyik(2012), for example, found that memory strategies positively correlated with academic success.

The present study did not find a particular relation between vocabulary size and vocabulary learning strategies. This finding is in line with Waldvogel's (2013) study and Tanyer and Öztürk's study (2014). Waldvogel's (2013) study found no relationship between vocabulary size and vocabulary learning strategies. The study conducted by Kalajahi and Pourshahian (2012) on the relationship between VLS and vocabulary size also showed that there were no considerable correlations between VLS and vocabulary size of EFL learners in Cyprus. In addition, althoughTanyer and Öztürk (2014) found that vocabulary learning strategies of students explained $17.8 \%$ of the variation in their vocabulary size, no correlation was found between particular vocabulary learning strategies and vocabulary stock. In contrast, Şener (2009) worked on the relationship between the use of vocabulary learning strategies and vocabulary size in the Turkish context and found that students using vocabulary learning strategies more frequently did better in the Vocabulary Levels Test (VLT). Therefore, it is not possible to claim that vocabulary learning strategies have a particular effect on vocabulary size.

\section{Conclusion}

We learn from the related literature that VLSs have been studied in relation to a number of different variables and different studies found different patterns of VLS use and different correlation patterns between VLS and vocabulary size. The present study found a moderate-to-high level of VLS use on the part of EFL learners and a moderate level of vocabulary size. As was stated above, there are a few studies that have been carried out on the relation between vocabulary size and VLS use. Some of them did not find any particular VLS that specifically correlated with vocabulary size, while some others found that determination strategies correlated with vocabulary size (Tanyer and Öztürk, 2014). Another study found (Alemdari, 2010) a relation between cognitive, determination and social strategies and vocabulary size. The present study did not find any specific correlation between VLS and vocabulary size.Although, as was stated, the literature produced different patterns in terms of VLS use and vocabulary size, as Nation (2001) states, there is no doubt that instruction on VLS will definitely help students in their vocabulary learning process.

In addition, studies on strategy training indicate that training helps learners develop their VLS. Aktekin and Güven (2007), for example, worked on raising learners' and teachers' awareness on vocabulary learning strategy and found that giving vocabulary learning strategy instruction to the study group had significant positive effect on the vocabulary learning of students.AtayandOzbulgan (2007) also claimed that "the instruction seemed to help them to 
self-diagnose their learning difficulties, experiment with both familiar and unfamiliar strategies, and self-evaluate their performance" (p.47). Moreover, Kök and Canbay (2011) investigated the effects of strategy training on vocabulary learning and use of vocabulary consolidation strategies and they found that strategy training increased the participants' strategy use. Therefore, it can be said that although studies reveal varying patterns of VLS use and varying levels of correlation between VLS and vocabulary size, as we can understand form the stated studies, instruction training helps learners develop their VLS use. In this case, language teachers must help their students in improving their VLS use.

\section{References}

Aktekin, C., \& Güven, S. (2007). Raising learners" and teachers" awareness of vocabulary strategy learning. Procedia Social and Behavioral Sciences, 13, 72.

Alamdari, Z., S. (2010). The relationship between vocabulary learning strategies employed by university level English language learners and their success.Unpublished master's dissertation.Hacettepe University, Ankara.

Alderson, J.C. (2005). Diagnosing foreign language proficiency. London: Continuum.

Atay, D., \& Ozbulgan, C. (2007). Memory strategy instruction, contextual learning and ESP vocabulary recall. English for Specific Purposes, 26, 39-51. http://dx.doi.org/10.1016/j.esp.2006.01.002

Boonkongsaen, N., \& Intaraprasert, C. (2014). Use of English Vocabulary Learning Strategies by Thai Tertiary-Level Students in Relation to Fields of Study and Language-Learning Experiences. English Language Teaching, 7(5), 59-70. http://dx.doi.org/10.5539/elt.v7n5p59

Cameron, L. (2001). Teaching languages to children. Cambridge: Cambridge University.

Catalan, R. (2003). Sex differences in L2 vocabulary learning strategies. Applied Linguistics, 13(1), 54-77. http://dx.doi.org/10.1111/1473-4192.00037

Coxhead, A. (2000). A new academic word list. TESOL Quarterly, 34(2), 213-238 http://dx.doi.org/10.2307/3587951

Ellis, N. (1995). The psychology of foreign language vocabulary acquisition: Implications for CALL. Computer Assisted Language Learning, 8(2-3), 103-128. http://dx.doi.org/10.1080/0958822940080202

Ellis, N. (2002). Frequency effects in language processing: A review with implications for theories of implicit and explicit language acquisition. Studies in Second Language Acquisition, 24, 143-188. http://dx.doi.org/10.1017/S0272263102002024

Gu, P.Y. (2003). Vocabulary Learning in a Second Language: Person, Task, Context and Strategies. Teaching English as a Second or Foreign Language TESL-EJ, 7(2), 1-25.

Gu, Y., \& Johnson, R. K. (1996). Vocabulary Learning Strategies and Language Learning Outcomes. Language Learning, 46, 643-697. http://dx.doi.org/10.1111/j.1467-1770.1996.tb01355.x

Hamzah, S. G., Kafipour, R., \& Abdullah, S. K. (2009). Vocabulary learning strategies of Iranian undergraduate EFL students and its relation to their vocabulary size. European Journal of Social Sciences, 11(1), 39-50.

Hirsh, D., \& Nation, P. (1992). What vocabulary size is needed to read unsimplified texts for pleasure? Reading in a Foreign Language, 8(2), 689-96.

Kafipour, R., Yazdi, M., Soori, A., \& Shokrpour, N. (2011). Vocabulary levels and vocabulary learning strategies of Iranian undergraduate students. Studies in Literature and Language, 3(3), 64-71.

Kalajahi, S.A.R., \& Pourshahian, B. (2012). Vocabulary Learning Strategies and Vocabulary Size of ELT Students at EMU in Northern Cyprus. English Language Teaching, 5(4).

Kök, İ., \& Canbay, O. (2011). An experimental study on the vocabulary level and vocabulary consolidation $\begin{array}{lllll}\text { strategies. Procedia Social and Behavioral Sciences, } & \text { 15, }\end{array}$ http://dx.doi.org/10.1016/j.sbspro.2011.03.206

Komol, T., \& Sripetpun, W. (2011). Vocabulary learning strategies employed by undergraduate students and its relationship to their vocabulary knowledge. Proceedings of the 3rd International Conference on Humanities and Social Sciences, Prince of Songkla University.

Laufer, B. (1997). The lexical plight in second language reading: Words you don't know, words you think you know 
and words you can't guess. In J. Coady\& T. Huckin (Eds.), Second language vocabulary acquisition: A rationale for pedagogy (pp. 20-34). New York, NY: Cambridge University Press.

Laufer, B. (1997). What's in a word that makes it hard or easy: Some intralexical factors that affect the learning of words. In N. Schmitt \& M. McCarthy (Eds.), Vocabulary: Description, Acquisition, and Pedagogy (p.140-155). Cambridge: Cambridge University.

Lawson, M. J., \& Hogben, D. (1996). The vocabulary learning strategies of foreign-language students. Language Learning journal, 46, 101-135. http://dx.doi.org/10.1111/j.1467-1770.1996.tb00642.x

Merikivi, R., \& Pietilä, P. (2014). Vocabulary in CLIL and in Mainstream Education. Journal of Language Teaching and Research, 5(3), 487-497.http://dx.doi.org/10.4304/jltr.5.3.487-497

Nation, P. (1983). Testing and teaching vocabulary. Guidelines, 5, 12-25.

Nation, P. (1990). Teaching and learning vocabulary. Boston, Mass.: Heinle\&Heinle.

Nation, P. (2001). Learning vocabulary in another language. Cambridge: Cambridge University. http://dx.doi.org/10.1017/CBO9781139524759

Nation, P. (2005). Teaching and learning vocabulary. In E. Hinkel (Ed.), Handbook and research in second language teaching and learning (pp. 581-595). New Jersey: Lawrence Erlbaum.

O’Malley, L., Chamot, A., Stewner-Manzanares, J., Kupper, C., \& Rocco P. R. (1985). Learning strategies used by beginning and intermediate ESL students. Language Learning, (35), 21-46.

Oxford, R. (1990). Language learning strategies: What every teacher should know. Boston: Newbury House.

Pulido, D. (2004). The relationship between text comprehension and second language incidental vocabulary acquisition: A matter of topic familiarity? Language Learning, 54(3), 469-524. http://dx.doi.org/10.1111/j.0023-8333.2004.00263.x

Pulido, D. (2009). How involved are American L2 learners of Spanish in lexical input processing tasks during reading? Studies in Second Language Acquisition, 31(1), 31-58. http://dx.doi.org/10.1017/S0272263109090020

Schmitt, N. (1997). Vocabulary Learning Strategies. In Schmitt, N., and McCarthy, M., Vocabulary: Description, Acquisition and Pedagogy. Cambridge: Cambridge University Press.

Schmitt, N. (2000). Vocabulary in language teaching. New York: Cambridge University.

Stæhr, L. S. (2008). Vocabulary size and the skills of listening, reading and writing. Language Learning Journal, 36(2), 139-152. http://dx.doi.org/10.1080/09571730802389975

Tanyer, S., \& Öztürk, Y. (2014). Pre-service English Teachers Vocabulary Learning Strategy Use and Vocabulary Size: A Cross-sectional Evaluation. Journal of Language Teaching and Research, 5(1), 37-45. http://dx.doi.org/10.4304/jltr.5.1.37-45

Tilfarlığlu, F.F.Y., \& Bozgeyik, Y. (2012). The Relationship between Vocabulary Learning Strategies and Vocabulary Proficiency of English Language Learners. International Journal of Applied Linguistics \& English Literature, 1(2), 91-101. http://dx.doi.org/10.7575/ijalel.v.1n.2p.91

Tüm, G. (2012). Impact of Dictionary Type and Usage to Enhance Turkish Vocabulary in Teaching Turkish as a Foreign Language. Turkish Studies International Periodical for the Languages, Literature and History of Turkish or Turkic, 7(4), 3013-3023.

Waldvogel, D. A. (2013). The Relationships between Vocabulary Learning Strategies and Vocabulary Size among Adult Spanish Foreign Language Learners. Journal of Language Teaching and Research, 4(2), 209-219. http://dx.doi.org/10.4304/jltr.4.2.209-219 